\title{
La inocencia: configuración semiótica de una propuesta ética en el discurso lírico de Rómulo Bustos Aguirre*
}

Fecha de recepción: 8 de febrero de 2018

Fecha de aprobación: 15 de mayo de 2018

\section{Resumen}

En el presente artículo, exponemos, de la manera más sintética y exhaustiva posible, los resultados de una investigación desarrollada entre los años 2011 y 2013. Nuestro interés aquí es comunicar tanto los resultados como los aspectos más relevantes del análisis e interpretación realizados en doce poemas del autor colombiano Rómulo Bustos Aguirre. Ello nos permitirá mostrar cómo en dichos poemas se predica una propuesta ética. Para desarrollar nuestra exposición, focalizamos un poema representativo del conjunto, porque en él se replican aspectos de la configuración semiótica que hace de nuestro corpus una unidad. Nuestro fundamento teóricometodológico estuvo conformado por los aportes de la Semiótica del discurso de la escuela intersemiótica de París y el modelo de análisis sémico y léxico semántico de la Semántica interpretativa de François Rastier.

Palabras clave: condición moral; axiología fundamental; norma ética de la inocencia; prototipo de la inocencia; antimodelo.

Citar: Chico Quintana, R. A. (enero-junio de 2018). La inocencia: configuración semiótica de una propuesta ética en el discurso lírico de Rómulo Bustos Aguirre. La Palabra,(32), 181-200. doi: https://doi.org/10.19053/01218530.n32.2018.8173.

\section{Rafael Arturo Chico Quintana}

Docente titular e investigador de la Fundación Universitaria Colombo Internacional. Miembro de la Federación Latinoamericana de Semiótica y de la Asociación Mundial de Semiótica. Investigador adscrito al grupo de investigación CUYNACO. Magíster en Semiótica de la Universidad Industrial de Santander, profesional en Lingüística y Literatura de la Universidad de Cartagena.

rchico@unicolombo.edu.co

*Artículo de reflexión derivado del trabajo de investigación "La inocencia configuración semiótica de una nueva condición ético-existencial en la poética de Rómulo Bustos Aguirre". 


\section{la palabra}

\section{Innocence: Semiotic Configuration of an Ethical Proposal in the Lyrical Discourse of Rómulo Bustos Aguirre}

\section{Abstract}

This paper synthetically presents the results of a research project conducted between 2011 and 2013, communicating its results as well as relevant aspects of the interpretation and analysis process. Twelve poems by the Colombian author Romulo Bustos Aguirre were analyzed in order to disclose the ways in which their semiotic configuration expresses an ethical proposal. To demostrate the analysis process in depth, we will focus on a representative poem, chosen from the corpus which replicates aspects of the semiotic configuration unifying our corpus. The theoretical and methodological framework that support the interpretation and analysis process involve the Semiotic Discourse Analysis theory developed by the School of Paris, as well as the semic analysis and lexical-semantic models of the Interpretive Semantics theory developed by François Rastier.

Keywords: Moral condition; Axiological fundament; Ethical rule of innocence; Innocence prototype; Anti-model.

\section{Innocence: configuration sémiotique d'une affirmation éthique dans le discours lyrique de Rómulo Bustos Aguirre}

\section{Résumé}

Dans cet article, nous présentons de la manière la plus synthétique et exhaustive les résultats d'une recherche menée entre 2011 et 2013. Nous voulons communiquer les résultats et les aspects les plus pertinents de l'analyse et de l'interprétation effectuées dans douze poèmes de l'auteur colombien Rómulo Bustos Aguirre. Ainsi, nous démontrerons de quelle manière l'auteur construit une affirmation éthique dans ces poèmes . Pour mener à terme notre exposition, nous nous concentrerons sur un poème représentatif de l'ensemble, dans lequel sont évidents les aspects de la configuration sémiotique qui donnent à notre corpus une unité. Nous avons utilisé les théories et méthodologies de la sémiotique du discours de l'école intersémiotique de Paris et l'analyse semique et léxico-sémantique de la Semantique interprétative de François Rastier.

Mots-clés: condition morale; axiologie fondamentale; norme éthique de l'innocence; prototype de l'innocence; anti-modèle 
Quizás se trate solo de jugar con las palabras como un malabarista

Pero sucede acaso que ese malabarista se ha sumergido a tal grado en los lábiles objetos de ese juego que no advierte que su caída ocurrió ya alguna vez

O más posible aun: el malabarista y el público saben que han caído y simulan

Mas eso haría parte del juego

Se trata, entonces, de jugar el no juego, de enhebrar los ojos de medusa del espejo

Y así el desierto pueda cruzar por el ojo de la aguja $\mathrm{O}$ el blanco del ojo atravesar la flecha

Se trata de inventar una segunda inocencia Romulo Bustos Aguirre.

\section{Aspectos preliminares}

El presente artículo deriva de un trabajo de investigación desarrollado entre los años 2011 y 2013, cuyo objeto de estudio fue la obra poética del escritor bolivarense Rómulo Bustos Aguirre. Nuestro interés aquí es presentar, de la manera más sintética y exhaustiva posible, los resultados obtenidos en dicha investigación. Para tal fin, hemos reproducido parte del re- corrido interpretativo expuesto en el informe de investigación (Chico, 2013b) que sirvió de base para la redacción de presente texto. ${ }^{1}$ Ello nos obliga a precisar dos aspectos clave relativos a la constitución de

\footnotetext{
Recorrido interpretativo es una categoría analítica de la Semiótica del discurso. En buena medida, condensa el enfoque teórico-metodológico que condujo nuestra investigación. Básicamente, se refiere al ejercicio del análisis, atendiendo a las estructuras de la significación. Para nuestro caso, fueron de interés las operaciones de la enunciación y las estructuras figurativas, dado que nos permitieron acceder a las estructuras profundas, donde se encuentran los sistemas axiológicos que sustentan la práctica discursiva del sujeto lírico de Bustos. Nuestro recorrido llevó a una refiguración, algo que implica el haber seleccionado una voz dentro de la multiplicidad del tejido rizomático del texto poético o su polifonía. Esto es lo que aquí realizamos: llegamos a identificar un enunciador y una práctica discursiva que le es tan propia como para independizarse de las pretensiones autoriales y sus intereses personales. Si se entrevistara a Rómulo Bustos, podríamos confrontar una visión distinta a la que aquí describimos analíticamente. Es por ello que, la exhaustividad es un valor caro para nosotros. Si reconstruimos esa identidad discursiva y su propuesta, es porque nuestro recorrido trató de describir, con el mayor detalle posible, la organización de los conjuntos significantes y cómo llegan estos a soportar la propuesta ética enunciada en el corpus de nuestra investigación. Enfoques teóricos para aproximarse al texto lírico abundan, como se puede apreciar en trabajos actuales; mas, un común denominador se podrá apreciar en varios de ellos y es la preocupación por la interpretación, sin hacer mucho énfasis en la descomposición de los mecanismos y operaciones estructurales que garantizan la posibilidad del ejercicio interpretativo. Ejemplos de enfoques a los que aquí aludimos se pueden encontrar en los trabajos: Anhelo cognitivo y muerte del ideal en la lírica colombiana (Santos, 2014), Sobre la enunciación poética y el doble: una aproximación a la poesía de Alejandra Pizarnik (Escobar, 2015). Particularmente, nuestro recorrido interpretativo sigue un curso opuesto al que Edson Guáqueta (2016) realiza en su artículo Lugar de enunciación y procedimientos poético de "España, aparta de mí este caliz" de César Vallejo. De hecho, su noción de enunciación es distinta a la nuestra, ya que él no establece la distinción entre plano de la enunciación presupuesta y plano de la enunciación enunciada (ver nota 9), lo que le lleva a rastrear en el poema los indicios de una voz autorial o espejo de los factores ideológicos, históricos y personales determinantes del punto de vista del poeta César Vallejo y cómo ello se configura en las operaciones de la enunciación del poema.
} 
nuestro corpus. En primer lugar, nuestra selección la componen doce poemas tomados de la obra completa publicada hasta el año 2013, excluyendo los textos del libro La pupila incesante, dada su muy posterior fecha de aparición (2016) bajo el sello editorial Fondo de Cultura Económica. En segundo lugar, es necesario especificar que dentro de esta selección de textos destacan tres poemas: $L a$ culpa, La inocencia y Quizás se trate de jugar con las palabras como un malabarista. Estos pueden ser tomados como ejemplares representativos de todo el conjunto. Los dos primeros lo son porque definen el paradigma $^{2}$ fundamental de la propuesta ética del discurso de Bustos, mientras que el último funciona como un espejo de todo el conjunto; es decir, este último poema replica la configuración semiótica que hace de los doce poemas una unidad y una propuesta.

El carácter especular de este último poema es de relevancia para los fines del presente artículo, debido a que refleja dos rasgos unificadores del corpus. El primero tiene que ver con una recurrencia común a todos los textos de la selección, y es la de un punto de vista dominante. En el corpus, se manifiesta la voz de un sujeto lírico que asume la enunciación del conjunto desde una competencia cognitiva determinada por lo que hemos llamado cognición mínima del sistema normativo de la inocencia (ver figura 1). Lo segundo tiene que ver con la operación retórica que hace posible la puesta en discurso de dicho punto de vista y que, además, nos permite conocer el modo en el cual este evalúa y sanciona, por un lado, a lo que hemos llamado el antimodelo moral y, por el otro, a lo que decidimos denominar el prototipo de la inocencia (ver figura 2). ${ }^{3}$ Hacemos referencia a la ratiocinatio, la cual es definible como el intento por conseguir una consecuencia lo suficientemente verosímil (creíble) para alcanzar la comprobación de un «grado indubitable de seguridad» que sirva de base segura para «levantar un argumentum» (Lausberg,1966, pp. 307-308).

El carácter especular del tercero de los poemas explica, además, nuestra decisión de encabezar el presente artículo con una cita in extenso del mismo y, lo más importante, que el desarrollo de nuestra exposición focalice varios de sus versos. Así pues, las referencias a los otros poemas del corpus vienen mediadas por el recorrido interpretativo realizado sobre este texto ejemplar. Ahora bien, teniendo en cuenta que, a pesar de ello, no es posible cumplir plenamente con los fines de este artículo sin remitirnos a resultados de los análisis hechos a los otros poemas, articulamos los aspectos más relevantes de estos últimos. Es por ello que, a continuación, y a modo de prerrequisito de nuestra exposición, reproducimos y explicamos dos esquemas fundamentales tomados del informe final de nuestra investigación (Chico, 2013b, pp. 142143). Esto nos permitirá ofrecer una visión más o menos global de cómo el punto de vista realiza la puesta en discurso en el corpus de poemas a través de la operación retórica de la ratiocinatio. Con base en esta descripción analítica, abordaremos, luego, en el apartado siguiente, los detalles del recorrido interpretativo que aquí nos compete.

\footnotetext{
Empleamos el término paradigma en el sentido tradicional que da la lingüística.

El Fontanille de Semiótica del discurso define el parangón como uno de los tipos de categorización; en otras palabras, como una de las formas en las cuales la realidad y los objetos que la componen son clasificados y comprendidos. Específicamente, el paragón es definible como el mejor ejemplar posible de una clase, aquel que posee en sí todas o la mayor parte de las propiedades representativas de una clase, cosa que le convierte en el lugarteniente de todos objetos que puedan agruparse dentro de ella (Fontanille, 2001, pp. 40-43). Es importante aclarar aquí, que si bien estamos de acuerdo con la concepción de Fontanille, preferimos usar un término similar al usado por el traductor de Fontanille, pero más ajustado nuestro discurso analítico acerca de la obra poética de Rómulo Bustos.
} 


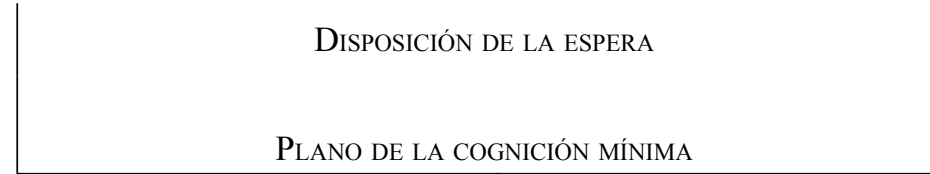

Sistema axiológico

Norma

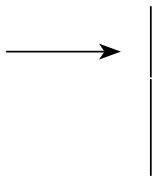

Valencias

$\downarrow$

I

Inocencia es no victimizarse: inocencia es aceptar la propia culpa.

\section{II}

Inocencia es no gozar con la muerte/destrucción del Otro: Inocencia es no convertir la muerte/destrucción en espectáculo.

\section{III}

Inocencia es no provocar la angustia y la congoja en el Otro: inocencia es no llevar al Otro al sufrimiento.

\section{IV}

Inocencia es no ceder el derecho a decidir sobre propio valor moral: ser inocentes es no deber renunciar a comprender el valor ético inherente.

\section{$\underline{\mathbf{V}}$}

Inocencia no es semiótica de la mezcla: inocencia no es renunciar a la búsqueda de perfección moral en favor de valores dudosos.
DISFORIA

Plano De la EVAluación

Ratiocinatio o Recorrido reflexivo

Mundos posibles recreados en los poemas

Contemplación imaginal

$\downarrow$

Quizás se trate solo...

MONÓLOGO DEL MINOTAURO

MONÓLOGO DEL ACTOR

MONÓLOGO DEL VERDUGO

PARA UN MANUAL DEL INQUISIDOR SACRIFICIAL

MONÓLOGO DEL MINOTAURO

MONÓLOGO DEL VERDUGO

DE LA LEVEDAD

PARA UN MANUAL DEL INQUISIDOR SACRIFICIAL

CHASSMODIO

DE LA LEVEDAD

JANO

PARA UN MANUAL DEL INQUISIDOR

MONÓLOGO DEL ACTOR

DE LA LEVEDAD

MEDALLAS

PARA UN MANUAL DEL INQUISIDOR

Quizás se trate solo...

Figura 1. Esquema de la norma o sistema normativo de la inocencia. 
La tabla la componen tres columnas. La que hemos denominado Plano de la evaluación, lista los poemas del corpus en los que se configuran los mundos posibles que son objeto de la evaluación del sujeto lírico $\mathrm{u}$ operador de la ratiocinatio. A este plano, le llamamos, también, de la Contemplación imaginal, puesto que se podría entender como constituyente de un ejercicio de reflexión basado en el acto de imaginar esos mundos, dotándoles de verosimilitud suficiente para llegar al ya mencionado «grado indubitable de seguridad» (Lausberg,1966, pp. 307-308). Ahora bien, ese grado de seguridad, foco de interés del sujeto lírico, deriva de la evaluación de las figuras que actualizan el antimodelo moral y que, a su vez, evidencian la ausencia (potencialización) del prototipo de la inocencia. Esto tiene consecuencias. La primordial de ellas es la de configurar a un sujeto lírico que adquiere consciencia de la importancia del prototipo de la inocencia, lo cual le modaliza pasionalmente como instancia en disposición de la espera; es decir, interesado y esperanzado en hallar indicios de su manifestación en los mundos posibles. Sin embargo, en el plano de la Contemplación imaginal, el sujeto lírico se ve afectado (modalizado pasionalmente) por la disforia 4 que genera la ausencia de tal ideal.

A continuación, reproducimos el esquema descriptivo de la estructura de la evaluación ${ }^{5}$ implicada en el recorrido reflexivo o ratiocinatio:

Marco Regulativo de la nORma: Sistema de las valencias del no deber-ser

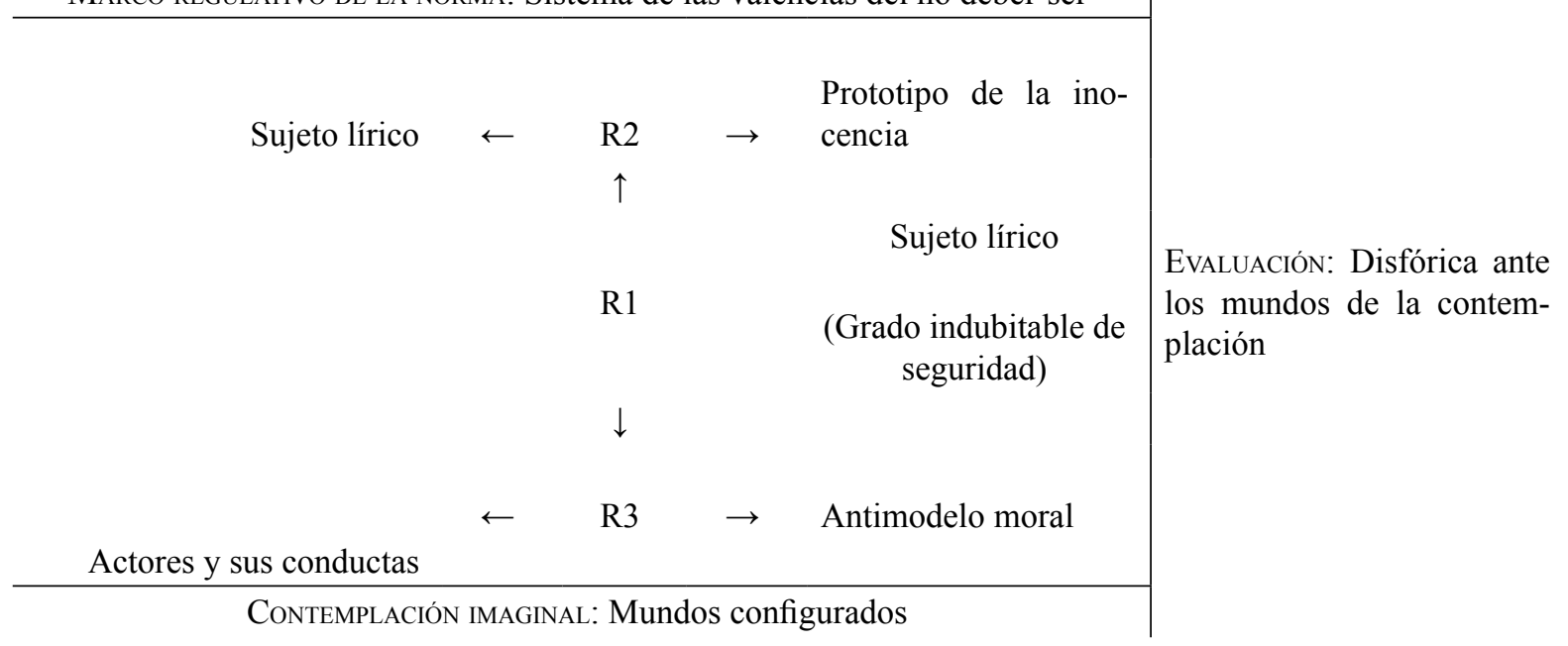

Figura 2. Plano de la evaluación.

Se notará que, en el esquema propuesto, el punto de vista evalúa disfóricamente (R1) el incumplimiento del Marco re- gulativo de la norma en el plano de la Contemplación imaginal, al adquirir grado indubitable de seguridad de la presencia o actualización del antimodelo moral, el cual es figurativizado o representado (R3) por los actores y sus conductas en los

$4 \quad$ El término disforia es manejado desde la perspectiva teórica de la Semiótica del discurso: «La disforia es el término negativo de la categoría tímica que sirve para valorizar los micro-universos semánticos, instituyendo lo valores negativos, y para transformarlos en axiologías. La categoría tímica se articula en euforia / disforia y comprende, como término neutro, la aforia» (Greimas \& Courtés, 1990, p. 130).

5 Para la representación esquemática del plano de la evaluación del recorrido reflexivo o ratiocinatio, hemos tomado en préstamo el modelo de la sanción postulado por Philippe Hamon (2012, pp. 22-27). 
mundos posibles configurados en los doce poemas. La evaluación, entonces, dependería del conocimiento (R2) que tiene el sujeto lírico sobre las valencias y valores que dimensionan el plano de la cognición mínima (ver figura 1) y a su ideal de sujeto y actor social: el prototipo de la inocencia.

\section{El recorrido reflexivo o la $\mathrm{ra}$ - tiocinatio}

Lo que a continuación presentamos extracta en buena parte lo expuesto en los capítulos finales de nuestro informe final de investigación (Chico, 2013b, pp. 115-159). Como ya explicamos, hemos escogido uno de los tres poemas ejemplares, dado su carácter especular. Retomamos, además, algunos apartes puntuales de los resultados de análisis de otros poemas y algunas de las conclusiones comunicadas en dos artículos de avances de investigación publicados con anterioridad a la fecha de finalización de nuestro trabajo de investigación.
En Enunciación y reforma (Chico, 2013a, pp. 85-102), denominamos recorrido reflexivo de la ratiocinatio al proceso que integra, primero, la recreación de los mundos posibles en los que se actualiza el antimodelo moral; segundo, el ejercicio evaluativo del contraste (R1 en la figura 2) ocurrido en la contemplación imaginal de los mismos; $\mathrm{y}$, tercero, la sanción disfórica a la que son sometidos tales mundos. Esto lo hemos sintetizado en los dos esquemas reproducidos anteriormente (ver figuras 1 y 2). Como ya mencionamos a propósito de ellos, estas operaciones enunciativas obedecen a la lógica bajo la cual se configura la ratiocinatio (Lausberg, 1966, pp. 307-308), la cual soporta la estructura de la evaluación que el sujeto lírico realiza a lo largo del recorrido reflexivo ${ }^{6}$ (ver figura 2). Para tal evaluación, como ya se dijo en la descripción del segundo esquema, es fundamental el conocimiento que el sujeto lírico tiene acerca de las valencias y valores que dimensionan la cognición míni- ma del sistema normativo de la inocencia.

En nuestra investigación, llegamos a reconstruir esta última, apoyados en el análisis de presuposiciones. Con esto queremos decir que al plano de la cognición mínima no se tiene acceso directo, dado que solo las figuras de las manifestaciones de los juicios de no-conformidad de la evaluación disfórica del sujeto lírico presentan indicios acerca del mismo. A este acceder al plano de la cognición mínima por medio del análisis de presuposiciones, le definimos como un retroceder hacia las estructuras que soportan la disposición de la espera; ya que, tal cognición se encuentra constituida tanto por la Norma como por el Sistema axiológico que soporta a esta última (ver figura 1). A continuación, reproducimos un esquema descriptivo de lo expuesto en este punto. Acompañamos dicho esquema de una breve explicación tomada de nuestro informe de investigación:

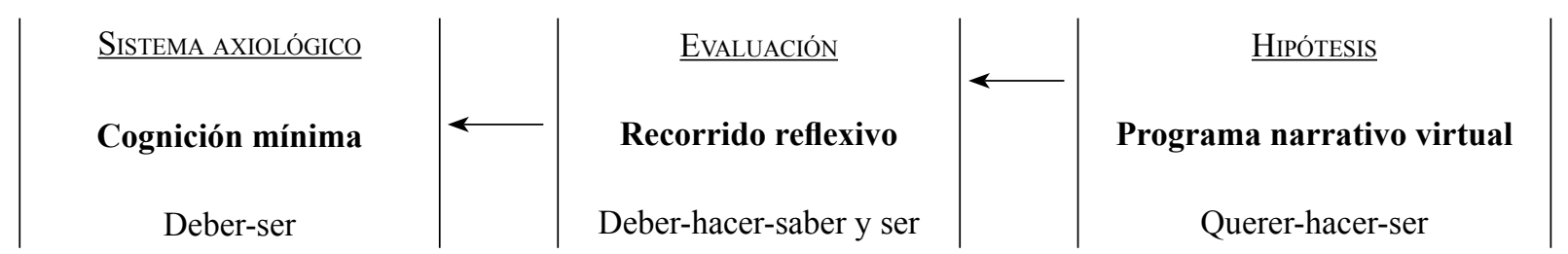

Figura 3. Secuencia lógico-discursiva del devenir de la hipótesis acerca de la inocencia.

$6 \quad$ Para mayores detalles sobre el concepto de recorrido reflexivo o configuración de la ratiocinatio, ver $\S 2.1 .1$ en nuestro informe de investigación La inocencia. Configuración semiótica de una nueva condición ético-existencial (Chico, 2013b, pp. 50-64). Para hacerse a una visión esquemática de los resultados de dicho análisis, ver la figura 9 incluida en ese mismo informe. En esta se ofrece una distribución de los textos que componen el corpus según la tensión entre el ideal de la norma predicada por el sujeto lírico y lo captado en los mundos de la contemplación imaginal. 
En resumidas cuentas, se diría que el sujeto lírico parte de la cognición mínima de lo éticamente correcto, lo que convoca la modalización del deber-ser, lo que deviene en un deber-hacer puesto en discurso por las operaciones del recorrido reflexivo hasta el momento descritas [...], lo que desemboca en la hipótesis enunciada por los versos del poema Quizás se trate de jugar con las palabras como un malabarista: "Se trata, I entonces, de jugar el no juego, / de enhebrar los ojos de medusa del espejo / Y así el desierto pueda cruzar por el ojo de la aguja / O el blanco del ojo atravesar la flecha / Se trata / de inventar una segunda inocencia" (Bustos, 2011, p. 35).

El sujeto lírico de Bustos Aguirre avanza la hipótesis de una alternativa válida en base a la evaluación de los mundos; a fin de cuentas, la ratiocinatio hace parte de lo que en retórica clásica se llama fase de la inventio, y que por definición corresponde a la "preparación poiética de la ejecución práctica"; en otras palabras, corresponde al momento de la gestación de un proyecto, una realidad virtualizada con posibilidades de actualización, algo que bien se puede identificar como la generación de un simulacro. En el caso del sujeto lírico de Bustos Aguirre, la hipótesis obedecería a un querer-ha- cer-ser; es decir, a la voluntad de transformar la manera cómo se configuran las relaciones éticas. Fundamenta su evaluación en un saber mínimo de base, "un universo semiótico sometido a concepciones modales, percibidas y categoriales". Lo que busca es garantizar la congruencia entre el ideal éticamente correcto y lo concreto de las relaciones intersubjetivas. Así, pues, se preocupa no por el sistema axiológico que soporta su punto de vista, sino por la formación de un modelo que opere a la hora de garantizar la realizabilidad del caso que mejor responda a la dimensión de lo éticamente correcto. La condición inocente sería, entonces la manifestación del parangón de la norma (sic). (Chico, 2013b, pp. 107-108) ${ }^{7}$.

Como se aprecia en la cita, los versos en cuestión explicitan el proyecto ético del sujeto lírico de Bustos, proyecto que, como ya mencionamos, es transversal a la puesta en discurso de los poemas de nuestro corpus. Esto destaca el carácter representativo de Quizás se trate sólo de jugar con las palabras como un malabarista. Ahora bien, es importante, en este punto, volver sobre algunos aspectos del plano de la evaluación, ampliando su explicación con referencias a lo que en Semiótica del discurso llamamos dimensión pasional.
La disforia suscitada a causa de la morfología de la contemplación imaginal, lleva hacia el surgimiento de la hipótesis o, más bien, de la propuesta ética predicada por el sujeto lírico. Esto es así porque a mayor grado de seguridad adquiere este del incumplimiento del ideal moral prescrito por la norma (figuras 1 y 2), menores posibilidades tendrá de captar el prototipo de la inocencia. Fontanille (2001, p. 109) explica que el llamado pivote pasional se da cuando el sujeto entiende cuál es el sentido de su estado pasional (la disposición). Es en ese instante, continúa Fontanille, cuando el sujeto que confronta los escenarios, sean estos positivos o amenazantes, es modalizado pasionalmente para actuar frente a ellos: podrá ser valiente o cobarde, si lo que confronta es amenazante, por ejemplo. En la sintaxis pasional que acompaña a la secuencia lógico-discursiva del devenir de la hipótesis acerca de la inocencia (figura 3), la reafirmación de la espera que se enuncia en los versos: "Se trata / de inventar una segunda inocencia" (Bustos, 2011, p. 35), podría ser vista como un acto de fe hacia los sistemas de valores que fundamentan la norma ética (ver figura 1) reguladora del punto de vista del sujeto lírico. Pero este estado, muy similar a lo que Fontanille llama pivote, no solo manifiesta un deseo o,

La expresión "realizabilidad" podría considerarse como un neologismo arbitrario, quizás erróneo. Pero lo que se intentaba dar a entender en el informe es que el sujeto lírico espera que el prototipo de la inocencia pueda concretarse y no que sea meramente una posibilidad. 
más bien, una demanda, también implica el tener voluntad: «Se trata, / entonces, de jugar el no juego, / de enhebrar los ojos de medusa del espejo» (Bustos, 2011, p. 35).

Ahora bien, comprender este modo de enunciar tal modalización o voluntad nos exige examinar con detalle la imagen poética puesta en discurso en estos últimos versos, lo mismo que hacer algunas precisiones acerca del poema del cual fue tomado. Básicamente, debemos tener en cuenta que el poema replica la configuración de la ratiocinatio y que esta pone en discurso dos mundos, acudiendo al dispositivo del simil ${ }^{8}$ (Chico, 2013b, p. 143): “Quizás se trate solo / de jugar con las palabras / como un malabarista" (Bustos, 2011, p. 35). Estos mundos configurados en el plano del discurso enunciado ${ }^{9}$ proponen dos posibilidades. Una donde el malabarista "se ha sumergido a tal grado / en los lábiles objetos de ese juego / que no advierte que su caída ocurrió ya alguna vez" y el otro donde "el malabarista y el público saben / que han caído y simulan" (Bustos, 2011, p. 35). Gracias al símil, el sujeto lírico establece una relación bastante explícita que define unos límites de interpretación ${ }^{10}$ altamente restrictivos, pues al malabarista solo se le puede entender como una figurativización de todo aquel que se dedique a la producción de discursos y su público como su consumidor o lector habitual:

\begin{tabular}{|c|c|c|c|c|c|c|c|c|}
\hline \multicolumn{4}{|c|}{ Fuente- Confrontación } & \multicolumn{5}{|c|}{ CONTROL - Mediación $\longrightarrow$ Blanco-Resolución } \\
\hline Dominio 1 & Operación & Dominio 2 & Dominio 1 & Operación & Dominio 2 & Dominio 1 & Operación & Dominio 2 \\
\hline $\begin{array}{c}\text { Campo } \\
\text { semántico } 1\end{array}$ & & $\begin{array}{c}\text { Campo } \\
\text { semántico } 2\end{array}$ & $\begin{array}{c}\text { Campo } \\
\text { semántico } 1\end{array}$ & & $\begin{array}{c}\text { Campo } \\
\text { semántico } 2\end{array}$ & $\begin{array}{c}\text { Campo } \\
\text { semántico } 1\end{array}$ & & $\begin{array}{c}\text { Campo } \\
\text { semántico } 2\end{array}$ \\
\hline $\begin{array}{l}\text { Jugar con } \\
\text { las palabras }\end{array}$ & Conflicto & Acto del & $\begin{array}{l}\text { Jugar con } \\
\text { las palabras }\end{array}$ & Énfasis & Acto del & $\begin{array}{l}\text { Jugar con } \\
\text { las palabras }\end{array}$ & Homología & Acto del \\
\hline & $\neq$ & $\begin{array}{c}\text { Malabaris- } \\
\text { mo }\end{array}$ & & $\geq$ & $\begin{array}{c}\text { Malabaris- } \\
\text { mo }\end{array}$ & & $=$ & $\begin{array}{c}\text { Malabaris- } \\
\text { mo }\end{array}$ \\
\hline
\end{tabular}

Figura 4. Dispositivo del símil.

Mas, ello no se refiere a cualquier tipo de producción sino a aquellas que, si bien deberían ser tomadas con seriedad, son tratadas como lúdica: "Mas eso haría parte del juego / Se trata, / entonces, de jugar el no juego" (Bustos, 2013, p. 35). El texto, entonces, propone una reflexión sobre la legitimidad de las prácticas discursivas y de los actores que gozan del derecho al uso de la palabra (Chico, 2013b, p. 146). Para el sujeto lírico, la lúdica con las palabras implica eludir una responsabilidad, la de crear el sentido de la segunda inocencia. Salta a la vista, entonces, que lo captado por él en esos mundos es una nueva violación al marco regulativo de la norma (figura 1).

8 Por definición, un símil es la operación retórica que deshace un conflicto semántico o incompatibilidad entre campos semánticos. En el caso estudiado, el de la producción discursiva y el del espectáculo del malabarismo. Para deshacer tal conflicto, el enunciador, el sujeto lírico, pone énfasis en uno de los campos tratándole como si fuese equivalente. Lo que ocurre es que con su asunción fuerza a entender un campo en los términos del otro. El resultado es la homologación que hace a un término sinónimo del otro. Para otros detalles acerca de esta perspectiva semiótica acerca del funcionamiento del símil ver La dimension rhétorique du discours: les valeurs en jeu (Fontanille, 2008, pp. 17-34).

$9 \quad$ Se hace uso de las categorías del modelo de los planos de enunciación de Eduardo Serrano (1996; 2007), quién distingue entre un plano de la enunciación presupuesta, donde se instalan los sujetos pragmáticos de la comunicación (autor y lector), un plano de la enunciación enunciada, donde se configuran los actantes posicionales de la comunicación (enunciador y enunciatario), y un plano del discurso enunciado, donde se organiza el universo referenciado o simulacro (universo del relato o de la descripción o de la argumentación o etc.).

10 Hablamos de límites de interpretación bajo los términos de Umberto Eco (1992). 
Siguiendo el hilo de las anteriores precisiones, a continuación, hacemos una interpretación de la imagen poética enunciada en los versos.

Lo primero a considerar es una figura: "los ojos de medusa del espejo". Tratar con ella exige tener en cuenta que la conforman dos constituyentes articulados mediante la contracción del: los ojos de la Medusa y su relación con el espejo. Sobre el primer constituyente, se sabe que la cultura occidental asigna el valor semántico disfórico / petrificación $/{ }^{11}$ como uno de sus rasgos inherentes, siguiendo así la tradición literaria y mítica grecolatina. Esto le ha prefigurado como un símbolo más o menos estable. En el universo sociolectal occidental, mirar a la Medusa entraña el peligro de la petrificación, lo que simbólicamente remite a la suspensión de las competencias: no se espera de un sujeto petrificado capacidad alguna para hacer. ${ }^{12}$ Pero, dicho símbolo es puesto en relación con la figura del 'espejo', el cual tiene el senti$d o:{ }^{13}$ "Tabla de cristal azogado por la parte posterior, y también de acero $u$ otro material bruñido, para que se reflejen en él los objetos que tenga delante" (DRAE) ${ }^{14} \mathrm{Al}$ hacerlo, convoca los semas inherentes /reflejar/, /objeto/ y /tener delante/. Esto supone que 'los ojos de medusa' son reflejo de quién se pone delante del «cristal azogado» (Bustos, 2013, p. 35); en otras palabras, es la imagen del actor que se contempla y, debido a ello, se convierte en objeto, no en sujeto de hacer. Básicamente, ello implica que el actor, por acción propia, se transforma en actante construido por la dinámica del reflejo, que es atributo del espejo. Este último ascendería a la posición de sujeto que crea, mientras el actante que se pone delante se deja crear. Esto entraña suspender la propia capacidad para hacer, en favor del mecanismo del reflejo, dejándose, así, definir como la 'Medusa'. El actor es, entonces, artífice de su propia petrificación en objeto, por acción de sus ojos que no miran más allá de la imagen construida por el espejo.

En términos del propio poema, lo que se tiene es la representación figurativa del malabarista y su público petrificados por el juego con las palabras: uno atrapado en su eterno malabar de insustanciales artificios discursivos y los otros legitimando un contrato de connivencia, adictos al intercambio ilusorio. Esto neutraliza (virtualiza) la competencia para crear en estos mundos y, por ende, toda posibilidad de captar perfectamente el sentido de la inocencia, que es el proyecto ético del sujeto lírico. Los juegos inmorales de la deshonestidad de estos actores son lo denunciado. Si hablamos ahora de inmoralidad, es gracias al sentido del semema 'caída': "Abandono o pérdida de valores morales" (DRAE). Sin embargo, la imagen como unidad sintáctica viene a proponer la acción necesaria para trascender esta lúdica: "Se trata, / entonces, de jugar el no juego, / de

11 La terminología y el instrumental aplicado en los análisis sémicos y léxico semánticos proviene de la propuesta teórico-metodológica de François Rastier. Será regular el uso de los términos sema inherente y aferente. En líneas generales, un sema es una de las unidades constitutivas del significado de las palabras (sememas), que puede encontrarse fijado en la lengua (sema inherente) o en el sociolecto o en el texto (sema aferente). Se tendrán en cuenta también la categoría clasema. Dentro de ella, se ordenan el dominio semántico o clasema que agrupa clasemas de menor grado inclusivo, los taxemas, que, a su vez, contienen otras agrupaciones paradigmáticas, los ya mencionados sememas. Otro elemento del que se hará uso será la notación tipográfica: comillas simples para sememas, barra para los semas, barras dobles para los clasemas. (Rastier, 2005, pp. 8, 60, 47-68).

12 Un buen ejemplo del grado de influencia que ha tenido la semántica del símbolo de la Medusa sobre la cultura occidental son las reflexiones teóricas del psicoanálisis. Al respecto, ver el artículo La cabeza de Medusa de Sigmund Freud y, para una interpretación más reciente del símbolo, ver el trabajo de Guy Lavallée La envoltura visual del yo (2001, pp. 112-19).

13 El empleo del término sentido es aquí muy específico. Se debe entender como significado que difiere de otro a causa de la presencia de al menos un sema inherente, lo que les hace no conmutables (Rastier, 2005, pp. 83-85). A fin de evitar el equívoco con la categoría homónima de semiótica, en el presente artículo, se marcará tipológicamente con cursiva.

14 Para los análisis sémicos y léxico semánticos, nos apoyamos en la versión digital del Diccionario de la Real Academia Española, el cual se encuentra disponible en la dirección electrónica http://dle.rae.es/?id=bv56DEN. A lo largo del texto, acudiremos a las iniciales DRAE para hacer referencia a él. 
enhebrar los ojos de medusa del espejo" (Bustos, 2013, p. 35).

El acto de enhebrar comprende el sema /pasar de parte a parte/, lo que implica abandonar un espacio para llegar a otro. Tomando en cuenta que el acto también convoca la figura implícita 'hilo', se podría decir que lo propuesto por el sujeto lírico es reformar la mirada y el hacer del actante. Propone trascender la lúdica de «los ojos de medusa del espejo» por medio del jugar el no-juego, que implica «pasar la hebra» no por el ojo de la aguja, sino por los de la Medusa. El 'hilo' es la nueva mirada que no se deja petrificar en los mundos configurados en el plano del discurso enunciado. Es la mirada honesta que hace un corte en el continuum de su existencia para captar-crear: "Se trata / de inventar una segunda inocencia" (Bustos, 2013, p.35). Esta mirada no es otra que la del sujeto lírico, ya que, al igual que con respecto a los mundos configurados en el plano del discurso enunciado de Quizás se trate solo de jugar con la palabras como un malabarista y en el de todos aquellos que son reunidos dentro de la contemplación imaginal del plano de la evaluación (ver figura 1), toma distancia crítica (desembraga enunciativamen- te) para instalarse en una parcela de su intimidad y, desde allí, reflexiona sobre la probidad de los actores y sus conductas, con el fin de tomar decisiones coherentes con el sistema axiológico.

El sujeto lírico es punto de vista modalizado por el querer-estar en conjunción con el prototipo de la inocencia y con ello responde de manera asertiva al deber-ser y estar en el mundo que soporta el marco regulativo de la norma (ver figura 1). Así, pues, se está frente a un sujeto de convicción plena $\mathrm{y}$, por tal motivo, convertido en expresión de una voluntad de igual grado. En el sistema funcional de la lengua, ${ }^{15}$ el semema "voluntad' comprende los sentidos: "1. f. Facultad de decidir y ordenar la propia conducta. 2. f. Acto con que la potencia volitiva admite o rehúye una cosa, queriéndola o aborreciéndola y repugnándola" (DRAE). Esto resulta coherente con la estructura del plano de la evaluación (ver figuras 1 y 2), dado que la evaluación disfórica supone algo más intenso que el simple rechazo hacia la inmoralidad hallada en los mundos de la contemplación imaginal. Al proyectar dichos mundos y oponerse categóricamente a lo que ellos representan, el sujeto lírico da muestras de querer /ordenar su propia conducta/. Ahora bien, 'voluntad' comprende también el sentido "Consentimiento, asentimiento, aquiescencia" (DRAE), cosa notablemente coherente con ese acto de fe o reafirmación del sistema axiológico, sustrato de su espera y del marco regulativo de la norma (ver figura 1).

Lo opuesto, ya se dijo, son los mundos de la contemplación incluidos en estos el del espectáculo inmoral del uso irresponsable de las palabras-. Todos ellos expresan únicamente un no deber-ser y estar conjunto al prototipo de la inocencia o, en otras palabras, el reprobable interés de definirse sin relación con él. Los actores de tales mundos carecen, por eso, de la fortaleza de la voluntad y prefieren tomar una decisión acomodaticia, un no querer-ser el prototipo. Es posible verlos como figuras de la 'desidia', ya que el semema comprende el sema inherente / inercia/ (DRAE); es decir, un dejarse llevar. Se podría confundir esto con adaptabilidad, pero, en los análisis de los poemas Sacrificial, Monólogo del minotauro, Monólogo del actor y Chassmodio pudimos notar que esa 'inercia' comporta la autosatisfacción egoísta, instrumentalista y destructora del Otro.

15 En oposición al sociolecto, el cual se define como el «Uso de una lengua funcional propio de un grupo social determinado» regido por unas normas lingüística de uso socializadas (Rastier, 2005, pp. 76, 359), el sistema funcional de la lengua atañe al sistema lingüístico restringido; es decir, tiene que ver con los sentidos y significaciones más generalizadas y comprensibles en el nivel de la isoglosa de la lengua (Rastier, 2005, pp. 76-86). Una forma de hallar estas estandarizaciones son los sistemas lexicográficos de los diccionarios reconocidos como autoridades. 
Ejemplo concreto es la imagen del público asistente al espectáculo configurado en Monólogo del actor. En él, se evidencia la euforia ante la ocurrencia de la muerte representada:

\section{Monólogo del actor}

De los varios papeles que he representado

el que más aplausos me ha cosechado

es el de víctima

Los antiguos hablaban de catarsis

Poco probable

es la actualidad del término

Extraños fervores de este público

que goza con mi muerte. (Bustos, 2004, p. 67).

Por tal motivo, la 'inercia' la entendemos como un dejarse llevar por el placer en la agresión. Sin embargo, no es la única forma que puede asumir. No menos inmoral es la reescritura acomodaticia del sistema normativo de la inocencia, tal como ocurre en la manipulación enunciada en el poema Para un manual del inquisidor, donde la violencia destructora se legitima bajo el precepto de un valor dudoso. En este poema, se recomienda al tú lírico sentir placer en la destrucción del Otro en nombre de la salvación de las almas, exigiéndole obediencia activa al código moral corrupto a cambio de ese placer:

Para un manual del inquisidor
No mirarás la mirada de la bruja

prescribe el Malleus Maleficarum

Podrás paladear la sal de su carne mientras le aplicas

El torno

Podrás disfrutar la flor áspera de su grito

Podrás olfatear su miedo mientras descoyuntas sus

/miembros

Pero no mirarás su mirada

Pues allí habita su más poderoso hechizo

Si lo hicieras estarías en sus manos, en sus ojos

Serías víctima entonces, de la temible compasión

Y habrás perdido todo tu esfuerzo para salvar su alma. (Bustos, 2004, p. 260).

Este no deber-ser y no querer-ser el prototipo de la inocencia, trazan el camino hacia el envilecimiento, porque dimensionan la desidia. Esta lleva a los actores de la contemplación imaginal a asumir una obligación: deber-no ser el prototipo $\mathrm{y}$, al encontrarse coaccionados por ello, actúan movidos por un deseo: un querer-no ser el prototipo de la inocencia. Ahora, lo que en un principio se mostraba como desidia o un dejarse llevar, se convierte en una trampa de la que no se puede salir. Son ejemplos de ello ese malabarista atrapado en el juego que ni se da cuenta de su propio fracaso e inmoralidad y el Sir Isaac New- ton del poema De la levedad, quien oficia como guardián de una falsa puerta del cielo. Este último se ve obligado a restablecer su legitimidad y autoridad mediante la tentación de las almas, pues solo corrompiéndolas y haciéndolas caer puede lograr que estas pierdan su natural condición de pureza o levedad, para hablar en lo términos del propio poema, y así ganar el peso de la vilesa que les haga entrar a un cielo perverso (Chico, 2011, pp. 117-119). Lo que resulta iluminador de este último poema es que tal corrupción se da también bajo la mediación del uso reprobable de las palabras:

Y el Guardián de la Puerta le sugirió que probara con /malas palabras

Y el alma leve dijo palabras crapulosas

que la censura celeste me impide repetir

Pero siguió levitando

Y el Guardián de la Puerta le sugirió que probara con /palabras inmundas

$\mathrm{Y}$ el alma leve dijo palabras abyectas

Que el asco me hace imposible repetir (Bustos, 2004, pp. 275-276).

Desde la mirada del sujeto lírico, el caer en dicha trampa es un acto de debilidad. Esto sería, desde su punto de vista, un rasgo característico de la conducta de los actores de la contemplación 
imaginal. Elegimos aquí el semema 'debilidad', ya que nos resulta lo suficientemente descriptivo para explicar la evaluación del sujeto lírico. Esto es así, porque el semema comprende entre sus sentidos la «Carencia de energía o vigor en las cualidades o resoluciones del ánimo» (DRAE). En el sistema funcional de la lengua, ese carecer de ánimo implica no tener valor, esfuerzo, energía, ni intención, ni voluntad (DRAE). La debilidad es el empobrecimiento completo del ser ético. Por lo tanto, el opuesto de tal debilidad debe conducir a la voluntad. Supone el estar modalizado por la negación de esa obligación vil del deber-no ser el prototipo.

Esto último es paso necesario para la configuración de una condición moralmente aceptable, dada su coherencia con la estructura de la norma (ver figura 1). Quién posea la voluntad, entonces, iría camino hacia su identificación con el ideal de sujeto y actor regulado por el sistema axiológico: el prototipo de la inocencia. Esto es así, porque ya no habría obligación de alejarse de tal identidad ética (no deber-no ser el prototipo), algo que es coherente con la enunciación del sujeto lírico en el plano de la evaluación (ver figura 2). Lo que sigue para quien opte por el camino de la voluntad, sería un no querer-no ser prototipo; es decir, tener como único deseo el identificarse plenamente con él. En el sistema funcional de la lengua, el opuesto de la 'debilidad' es la 'fortaleza'; sin embargo, el punto de vista del sujeto lírico no admite tal reducción. Lo más cercano es el semema 'determinación' el cual comprende los semas inherentes /distinguir/ y /discernir/; lo que es congruente con el recorrido reflexivo de la ratiocinatio. Otro sema comprendido es / tomar resolución/, este permite la aferencia de los semas /ánimo/, / valor o arresto/ (DRAE).

La sintaxis completa de todo lo descrito hasta el momento, la componen dos trayectorias. Una lleva a la debilidad, y se podría considerar como el tránsito hacia el envilecimiento. El valor definitorio de la condición ética implicada en esta primera ruta lo ofrece el paradigma estudiado en los poemas La Culpa y La Inociencia: se trata de la culpa (Chico, 2013b, pp. 117-153). La trayectoria contraría lleva hacia la voluntad y su valor es el opuesto: la inocencia.

Llegado este punto, se nos hace necesario denominar los recorridos que llevan de la desidia a la debilidad y de la determinación a la voluntad, para ello volveremos sobre el poema focalizado en este artículo: Quizás se trate solo de jugar con las palabras como un malabarista.

Como se concluyó en el artículo "Enunciación y reforma", un mundo posible ideal, diferente al que se configura en el plano del discurso enunciado del poema, exige un nuevo tipo de acuerdo entre los participantes del intercambio comunicativo o, en palabras del mismo poema, entre el malabarista y su público. A esto, ya le definimos más arriba como el jugar el no-juego. Lo que concluimos en "Enunciación y reforma" fue que un requisito insoslayable para esta no-lúdica es la honestidad en el sentido de "razonable y justo" (DRAE):

[Los actores] estarían en el deber ético de reflexionar sobre el sentido de sus prácticas y a evaluarlas en concordancia con la necesidad de dar paso al sentido. Obviamente, lo incompatible con ello es el extravío y la connivencia de quienes deciden ignorar la responsabilidad que contraen, un no deber-hacer posible la puesta en servicio del hacer discursivo que es malicia de quienes fingen no haber caído. (Chico, 2013a, p. 97).

Esto último es coherente no solo con el marco regulativo de la norma (ver figura 1), sino también con la configuración de las trayectorias antes enunciadas. Los resultados de ese acuerdo nuevo coincidirían con los trayectos que llevan de la desidia a la debilidad y de la determinación hacia la voluntad, ya que suponen desarrollar el ejercicio consciente de la reflexión para llegar la grado indubitable de seguridad $\mathrm{y}$, por ese mismo camino, a la aceptación de la responsabilidad sobre los propios actos. Lo contrario, como se expresa en la misma cita, corresponde a los universos 
de la desidia. Se nos hace necesario afirmar algo más. Ese contrato que promete «restablecer el estado natural de las prácticas discursivas y la obligación que imponen sobre los actores que en ellas participen» (Chico, 2013a, p. 97) se muestra coherente con la modalización de la espera del sujeto lírico y que no es otra que el desear un mundo acorde con el prototipo de la inocencia.

Ofrecemos ahora una esquematización de toda esta sintaxis:

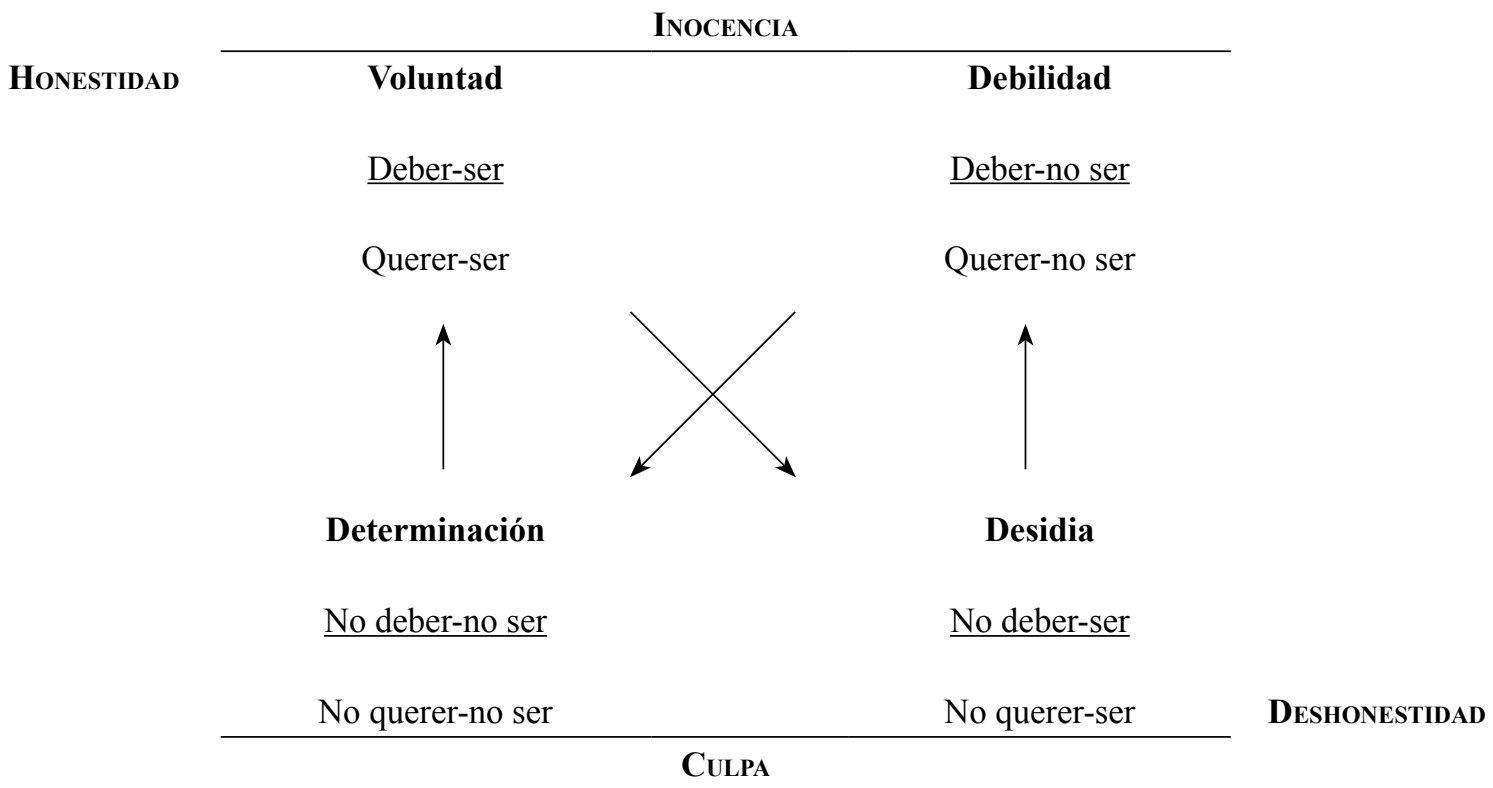

Figura 5. Sistema axiológico de la mediación de la honestidad (recorrido reflexivo).

Es importante precisar algo respecto a estos resultados. Con la reconstrucción de la sintaxis de las trayectorias y los valores asociados a ellas, el análisis ha dado cuenta de un sistema axiológico de transición. Este da sentido a las operaciones de la enunciación del sujeto lírico y explica la estructura de una polaridad o lo que podría llamarse el conflicto entre dos formas de vida orientadas hacia valores semánticamente solidarios, pero irreductibles a una conciliación, ya que entre ambos conforman el paradigma desde el cual el sujeto lírico define la condición ética de los ac- tores y sus conductas. También, resulta importante advertir aquí que entre los evaluados es necesario incluir al mismo sujeto lírico, quien, pese a su esfuerzo por mostrar distancia con el recorrido reflexivo, no puede escapar al ser categorizable dentro de la polaridad positiva del sistema: el de la honestidad. Esto es así, porque su propia conducta, identificable con su hacer discursivo (el recorrido reflexivo), bien representa los valores positivos por él predicados: la determinación y la voluntad como valores que soportan la trayectoria de la honestidad. Se podría concluir entonces que el sistema no es otra cosa que una de las manifestaciones de una estructura profunda determinante. Estructura que articularía categorías más generales. Tal sistema tendría como posición inicial los dos valores solidarios correspondientes al sistema axiológico (ver figura 1). Tales valores fueron derivados de los análisis realizados a los poemas La Inocencia y La Culpa (Chico, 2013b, pp. 117-143). Estos valores son la responsabilidad y la pureza, y dimensionan el deber-ser y estar en el mundo en que se apoya la estructura del marco regulativo de la norma. 
La forma de vida opuesta a ello es la de los mundos de la contemplación imaginal. Sus actores predican el querer-no ser el prototipo; es decir, la negación de los valores de la honestidad y el renunciar a la comprensión de la propia condición moral. A este respecto, nuestro análisis identificó algo curioso. Ello lo explicamos más arriba cuando tratamos el problema de la trampa en la cual caen los actores de Quizás se trate solo de jugar con las palabras como un malabaris$t a$ : ellos acaban inmersos en una dinámica que les impide acceder libremente a una formación moral correcta. Su condición moral queda definida por los valores contrarios: la irresponsabilidad y la impureza moral.

A diferencia de ellos, el sujeto lírico asume la responsabilidad de reflexionar sobre la legitimidad ética de los actores y sus conductas, se embarca libremente en la búsqueda del ideal y no renuncia a su empresa. Llega con grado indubitable de seguridad a saber que la inocencia es una condición moral hallable-construible. Este juicio epistémico se enuncia en los versos: "Se trata / de inventar una segunda inocencia" Este grado de seguridad explica que el sujeto lírico jamás dude de sus evaluaciones, y debido ello cumple con el objetivo establecido por la ratiocinatio: "La voluntas del orador es, pues, tan fuerte que deshace el tejido de mentiras del adversario y ayuda al triunfo de la verdad" (Lausberg, 1966, p. 85). La plena convicción del sujeto lírico evita defraudar (virtualizar) su espera. Cosa contraria ocurre del lado del plano de la contemplación imaginal, donde se instala la polémica:

\section{Estado ÉTICo}

ESPERA

(CONTRATO)

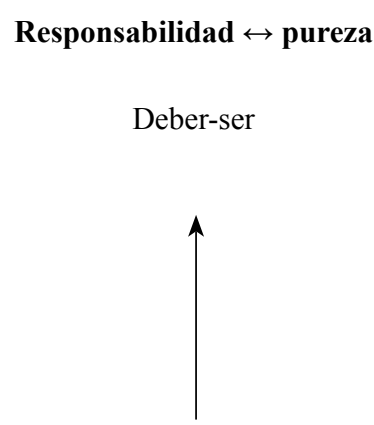

Honestidad

\section{(+)}

Creer-ser
(-)

Irresponsabilidad $\leftrightarrow$

impureza

Deber-no ser

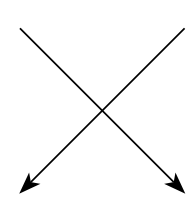

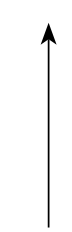

Deshonestidad

Querer-no ser

Polémica

CONDICIÓN MORAL

Figura 6. Sistema axiológico de la espera y la polémica.

Esto nos deja, nuevamente, frente a una polaridad estructural. De un lado, aquellos que entablan la polémica y anulan (virtualizan) el contrato, que incumplen las normativas, se dejan llevar por la fruición culpable, interpretan la norma acomodaticiamente, pero a fin de cuentas e irrevocablemente se ven condenados a carecer de libertad en el inmoral siste- ma axiológico que predican. $\mathrm{Su}$ evolución lleva de la polémica a la condición moral deshonesta, convirtiéndose en el antimodelo. El polo positivo lo ocupa el sujeto lírico y aquellos que 
coinciden con su punto de vista. $\mathrm{Al}$ asumir la responsabilidad de reflexionar sobre la condición ética y no dejarse llevar, reafirman su fe en el sistema axiológico y, por ende, confían en la probidad moral de su espera. $\mathrm{Su}$ evolución debe llevarlos a emular el prototipo de la inocencia.

Podemos brindar una descripción más completa del sistema axiológico ahora. Este articula la sintaxis del sistema axiológico de mediación (figura 5) y la del sistema axiológico de la espera y la polémica (figura 6). Este último subsume al primero, por lo que es posible establecer dos campos semánticos organizados por cadenas de implicaciones. En el primero de ellos, se organizan los valores positivos de ambos sistemas. La probidad moral aparece como valor que subsume a los demás, pero su realización depende de la solidaria semántica de los valores de la responsabilidad y la pureza. A su vez, esta implica la existencia de una forma de vida honesta, la cual se fundamenta en la voluntad que tengan los sujetos. Sin embargo, esta voluntad solo se realiza si se posee determinación suficiente para forjar la condición moral correcta, gracias al interés de llegar a ser prototipo de la inocencia. Esta búsqueda es el objetivo del sujeto lírico. Esto es así, porque el saber sobre cuál es el mejor ejemplar de la norma es lo que permite al sujeto lírico evaluar los mundos de la contemplación imaginal, al contrastar el ideal abstracto (la norma) y lo concreto (los mundos de la contemplación) (ver R1 en la figura 2). El eje de todo es el ideal.

Para el otro campo, la descripción no difiere más que en los valores de los polos negativos del Sistema axiológico de mediación (figura 5) y del Sistema axiológico de la espera y la polémica (figura 6). Aquí, el mejor ejemplar es el antimodelo u opuesto al sujeto inocente: el culpable.

Proponemos la siguiente esquematización completa del sistema axiológico:

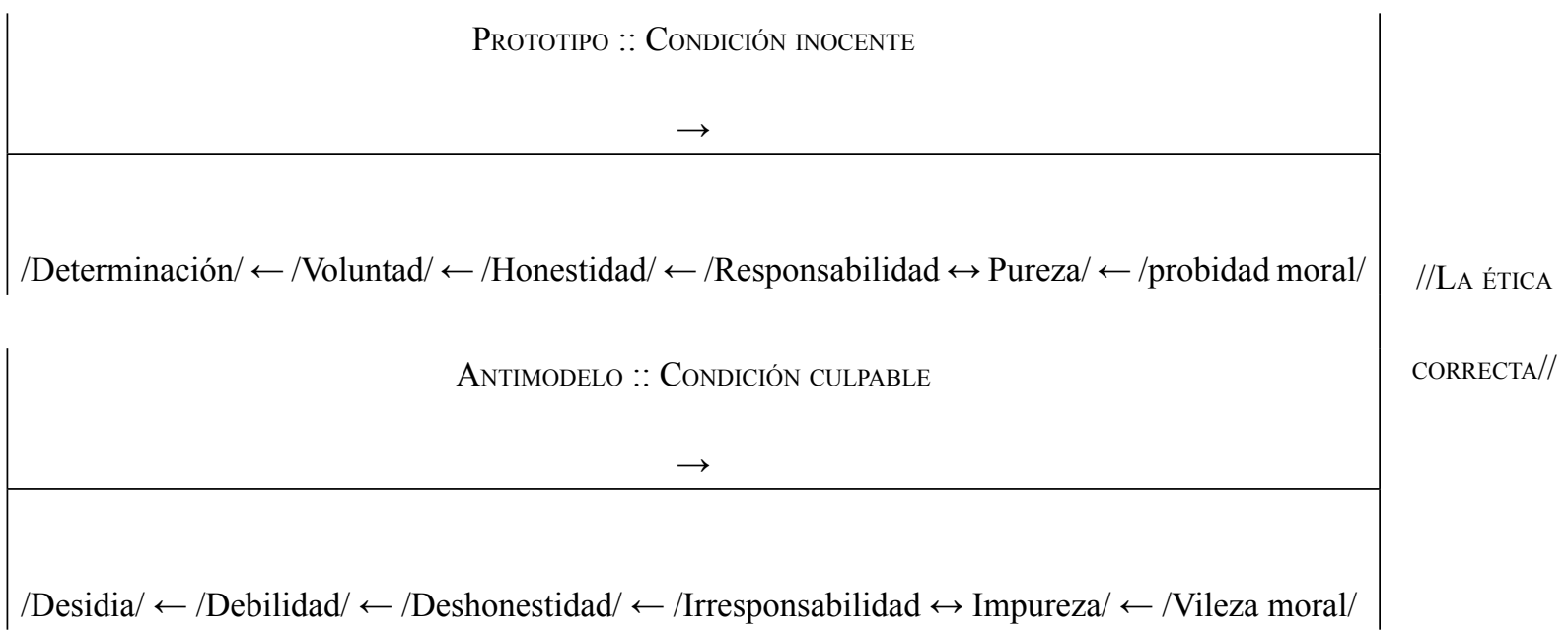

Figura 7. Esquema del sistema axiológico

\section{Conclusiones}

El sistema axiológico (figura 7) compone la cognición mínima (ver figura 1), que es conoci- miento sobre la Ética correcta. Esto modaliza pasionalmente (pasión de la espera) al sujeto lírico. Sin embargo, los mundos que él proyecta en la contem- plación imaginal no concuerdan con el ideal de la norma. Como ya se estuvo explicando, esto hace parte del ejercicio reflexivo que le lleva a reconocer la 
necesidad e importancia de las valencias y valores del sistema axiológico (ver figura 1). A su vez, estas le permiten distinguir cuál es la ausencia en los mundos de la contemplación. Dicha ausencia es el motivo de su disforia, pero también da pie para que llegue al grado indubitable de seguridad, pues, si bien no encuentra al prototipo de la inocencia o modelo de la probidad moral, cree en su existencia. Es por ello que, su estado y evolución pasional no acaba en pasión negativa, sino en una fe, tanto así que enuncia con toda resolución cuál es su deber y el de todos aquellos que coincidan con su punto de vista: «inventar la segunda inocencia».

Si se comparasen las operaciones del sujeto lírico de Bustos con las que debe hacer novicio jesuita en sus exercitia spiritualia, salta a la vista lo más interesante de su proyecto ético. ${ }^{16}$ A saber, el sujeto lírico nunca proyectó su contemplación, partiendo de relatos minuciosamente prediseñados para modelar la conducta. El novicio sí. Este los usa para responder afirmativamente a la norma y el sistema axiológico cristiano: «visualización, y después contemplación de escenas del infierno, de la Natividad, de la Huida a Egipto, de la Crucifixión, de la tan rara representación de la aparición de Jesús a su madre (verdadera segunda aparición en un ejer- cicio de aparición)» (Durand, 2000, p. 40).

La enunciación del sujeto lírico no se limita a generar copias exactas del ideal, al contrario proyecta los contraejemplos. Ello supone una actitud diferente. Aunque, de manera similar al novicio, el sujeto lírico de Bustos confirma su sistema axiológico y el marco regulativo de la norma, él no busca reafirmar su fe. La convicción le sobra. Él busca estudiar las conductas y las relaciones intersubjetivas, asumiendo una posición crítica ajena al relativismo y a la tolerancia. Prueba de ello, es su falta de reparos a la hora de condenar a un símbolo y modelo de la ciencia occidental y, a través de ello, al sistema axiológico que esta predica. Esto lo explicamos en el artículo "Del infierno merecido" (Chico, 2011, pp. 117119).

Pero, lo más singular de esta mirada es la concepción de inocencia y perfección moral que propone. Para el sujeto lírico de Bustos, la inocencia no es ni un estado de natural limpieza moral, ni la simple ausencia de culpa, tampoco es falta de conocimiento que disculpe de la acción reprobable; ejemplo es, como ya mencionamos, la sanción a la que somete a Sir Isaac Newton: este es condenado en el plano del discurso enunciado del poema De la levedad. Se le ve privado del saber y ejerciendo, dentro de sus limitaciones, lo que cree ser su responsabilidad: oficiar como guardián de la puerta del cielo, pero de un cielo que demanda la corrupción de las almas (Chico, 2011, pp. 117119). Para el sujeto lírico, es reprobable también el actuar en nombre de valores socialmente estimados, si ellos no concuerdan con la ética correcta (ver figura 7). El caso se presenta en el mundo configurado en el poema Para un manual del inquisidor (Chico, 2011, pp. 117-119).

Tal parece que la cognición mínima del sujeto lírico define un punto de vista altamente parcializado y muy asociado a valores ajenos al modo en el cual cotidianamente se concibe la inocencia en la cultura occidental. La enunciación es clara, se busca inventar una segunda inocencia; es decir, la intención es reformar los sistemas de valores y creencias asociados a ella. La inocencia parece más una competencia por adquirir que un estado ético. Lo cual lleva a pensar que, desde la mirada del sujeto lírico de Bustos, no se nace inocente ni la inocencia es una cualidad, es más bien un saber que se adquiere partiendo de la determinación (ver figura 7). El llegar a ser inocente implica reflexionar acerca de la condición moral propia y la del Otro. Se llega a ser puro gracias a un ejercicio racional que dote

16 Para mayores detalles acerca de estas reflexiones de Durand y del análisis que nosotros hacemos a partir de ellas, consúltese nuestro informe de investigación (Chico, 2013b, pp. 108-112). 
del conocimiento para repudiar lo inmoral. A ser inocente, se aprende, y con el tiempo se perfecciona.

En tal sentido, la práctica discursiva del sujeto lírico de Bustos, en tanto radicalización crítica frente a las concepciones convencionales acerca del estado de probidad moral, se instaura como una mirada singular y proyectada hacia la construcción de un sistema moral alternativo $\mathrm{y}$, en buena medida, incongruente respecto a lo que la cultura occidental moderna ha convertido en patrimonio de su sentido común y de sus instituciones legitimadas (moral judeo-cristiana, ética de la ciencia, etc.). Esto nos lleva a considerar que la postura del sujeto lírico de Bustos se inscribe dentro de una tradición de las prácticas discursivas de la literatura occidental. Nos referimos a las reflexiones éticas acerca del mundo moderno.

Dentro de tal tradición, hallamos un caso de radicalización del punto de vista, paralelo al de Bustos. Nos referimos a una de las novelas de Amélie Nothomb: Diario de Golondrina. Las obras de Bustos y Nothomb sintonizan en su malestar frente a la crisis de los sistemas axiológicos de la modernidad occidental, pero discrepan en el modo de asumir y reaccionar frente a ello. En la obra de Bustos, como hemos estado exponiendo aquí, la respuesta es también un acto de fe en una propiedad humana: la racionalidad que toma forma en el ejercicio analítico y evaluativo. Esto se materializa a través de la operación retórica de la ratiocinatio. Por su parte, en Nothomb, la enunciación sigue un curso distinto y más emparentado con una herencia romántica que ha sido determinante para las prácticas discursivas de la literatura y, en especial, de la poesía moderna: la contracultura. En Diario de Golondrina, ello se configura en los actos del narrador-protagonista, quien re-inventa su identidad siguiendo los caminos de lo abyecto. La corrupción es, para él, posibilidad de transformación moral necesaria (Chico, 2014, pp. 110-123). Este titanismo contracultural lleva, en la novela de Nothomb, a la revelación de la indentidad moral correcta, que, al igual que en Bustos, es una segunda inocencia.

El narrador-protagonista carece de nombre a inicios de la novela, luego asume la identidad abyecta contracultural bajo el nombre autoasignado de Urbano $\mathrm{y}$, al final, encuentra su verdadera indentidad ética bajo el nombre de Inocencio. Pero esta nueva condición moral, es distinta a la del sujeto lírico de Bustos, ya que no hay arrepentimiento por la corrupción que le precedió. La destrucción del Otro es aceptable en cuanto permiten la auto-reafirmación de la subjetividad. Sin embargo, este trasegar lleva después a una especie de "autismo" ético. El narrador-protagonista hace su apuesta final por una inocencia dada únicamente en una intimidad que no se comparte, que se vigila y prohíbe a los demás. Tanto es así que, el lector mismo es configurado como una perpetrador o criminal que trata de acceder a dicha intimidad vetada (Chico, 2014, pp. 123-124).

La propuesta de Bustos trasciende tal radicalización de cierre en la subjetividad y de pesimismo frente a la posibilidad de construir una condición moral sobre una ética correcta e incluyente, pues su apuesta es una búsqueda del aprender a saber ser y hacer los correcto para sí mismo y para el Otro (Chico, 2014, p. 125). En tal medida, esta forma de apertura a la alteridad, despeja una zona propia dentro de la tradición de la prácticas discursivas a la que hemos estado aludiendo. La voz de Bustos se hace espacio, oponiéndose a dos puntos de vista acerca la moral correcta. El primero es el encerramiento radical de la subjetividad o ética "autista" del Yo-bien del sujeto nothombeno; el segundo, es el contrario a este último. Betancur \& Areiza lo estudian en las novelas Foe y la Edad de Hierro de J. M. Coetzee, donde concluyen que la alteridad es algo de lo que hay que hacerse cargo debido a su carácter de espejo del sujeto y sus padecimientos (Betancur \& Areiza, 2017, pp. 12-13). A diferencia de esta ética del cuidado o de Lo que es el bien colectivo, la propuesta de Bustos no es un simple reconocimiento del padecimiento y la reparación, sino 
del aprendizaje y del análisis crítico del porqué se padece $\mathrm{y}$, también, de hasta qué punto se es responsable del padecimiento ajeno. Solo así se puede llegar a la construcción de una ética de los valores universales o De lo que es el bien.

\section{Referencias}

Betancur Valencia, D. B. \& Areiza Pérez, E. (2017). El lenguaje como exilio y el lenguaje como morada en las relaciones de alteridad: un acercamiento desde dos obras literarias de J. M. Coetzee. $L a$ Palabra, (30), 261-271. doi: https://doi.org/10.19053/01218530.n30.2017.6204

Bustos, R. (2004). Oración del impuro Obra reunida. Bogotá, D.C.: Universidad Nacional de Colombia.

Bustos, R. (2011). Muerte y levitación de la ballena. Cali: Universidad del Valle.

Chico, R. (2011). Del infierno merecido. Mecánicas de la sanción y el deslizamiento en el discurso lírico de Rómulo Bustos Aguirre. Revista S, 5, 11-125.

Chico, R. (2013a). Enunciación y reforma. Sapiens, (14), 85-102.

Chico, R. (2013b). La inocencia Configuración semiótica de una nueva condición ético-existencial en la obra poética de Rómulo Bustos Aguirre. (Tesis de maestría). Universidad Industrial de Santander, Bucaramanga, Colombia.

Chico, R. (2014). La formación de la identidad abyecta como respuesta ética de contracultura. La Palabra, (25), 108-126. doi: https://doi.org/10.19053/01218530.2875

Durand, G. (2000). Lo imaginario. Barcelona: Bronce.

Eco, U. (1992). Los límites de la interpretación. Barcelona: Lumen.

Escobar, M. (2015). Sobre la enunciación poética y el doble: una aproximación a la poesía de Alejandra Pizarnik. La Palabra, (26), 129-136. doi: https://doi.org/10.19053/01218530.3253

Fontanille, J. (2001). Semiótica del discurso. Lima: Fondo de Cultura Económica.

Fontanille, J. (2008). La dimension rhétorique du discours: les valeurs en jeu. En J.-M. e. Klinkenberg, Figures de la figure (pp. 17-34). Limoges: Pulim.

Freud, S. (1974). Obras completas. Madrid: Biblioteca nueva. 
Greimas, A.-J., \& Courtés, J. (1990). Semiótica Diccionario razonado de la ciencia del lenguaje. Madrid: Gredos.

Guáqueta, E. (2016). Lugar de enunciación y procedimientos poéticos de "España aparta de mí este caliz” de César Vallejo. La Palabra, (28), 127-139. doi: https://doi.org/10.19053/01218530.4792

Hamon, P. (2012). Texto e ideología. Bogotá: Instituto Caro y Cuervo.

Lausberg, H. (1966). Manual de retórica literaria (Vol. I). Madrid: Gredos.

Lavallée, G. (2001). La envoltura visual del yo. Madrid: Biblioteca Nueva.

Rastier, F. (2005). Semántica interpretativa. México: Siglo XXI.

Real Academia Española. (2013). Real Academia española. Recuperado el 28 de agosto de 2012, de Diccionario de la Real Academia Española: http://rae.es/rae.html

Santos, E. (2014). Anhelo cognitivo y muerte del ideal en la lírica colombiana. La Palabra, (24), 45-58.

Serrano, E. (1996). La narración literaria. Cali: Gobernación del Valle del Cauca.

Serrano, E. (2007). Voces textuales y voces discursivas. Poligramas, 1-25. 